\title{
Endoscopic Full Thickness Resection for Gastrointestinal Tumors - Challenges and Solutions
}

\author{
Hung Leng Kaan ${ }^{1}$ and Khek Yu Ho ${ }^{2}$ \\ ${ }^{1}$ Department of General Surgery, National University Hospital, Singapore, ${ }^{2}$ Department of Medicine, Yong Loo Lin School of Medicine, \\ National University of Singapore, Singapore, Singapore
}

Standard polypectomy, endoscopic mucosal resection, and endoscopic submucosal dissection (ESD) are established techniques for the treatment of gastrointestinal tumors. However, resection of submucosal tumors via ESD often results in low rates of microscopically margin-negative (R0) resection and high rates of perforation. Endoscopic full thickness resection (EFTR) overcomes this adverse event and aids in the therapeutic management of complex tumors.

Multiple techniques for EFTR have been developed, each with its own advantages and disadvantages. Submucosal tunneling and nonexposed techniques are generally preferable, because the layer of overlying intact mucosa reduces the incidence of intraperitoneal contamination by the gastric fluid and dissemination of the tumor cells. However, adoption of EFTR by endoscopists in clinical practice remains low. The major challenge seems to be the technical difficulty in performing laparoscopic and/or endoscopic suturing using the currently available instruments.

We developed a novel robotic endoscopic platform with suturing capabilities to overcome the technical challenges of suturing. This platform allows easy maneuvering and triangulation of the instruments, thus facilitating endoscopic suturing using robotic arms. Our studies have demonstrated that this robotic endoscopic platform with suturing capabilities is an effective and safe method for performing EFTR with endoscopic suturing. Clin Endosc 2020;53:541-549

Key Words: Endoscopic full thickness resection; Endoscopic suturing; Robotics; Submucosal tumors

\section{INTRODUCTION}

While endoscopic submucosal dissection (ESD) is an established treatment method for gastric adenoma and early gastric cancer, ${ }^{1}$ it remains a suboptimal option for the treatment of a subgroup of lesions such as subepithelial tumors arising from the muscularis propria. Performing ESD for such tumors often results in low rates of microscopically margin-negative (R0) resection and has a higher risk of perforation. ${ }^{2-4}$ When

Received: August 15, 2019 Revised: December 2, 2019

Accepted: December 10, 2019

Correspondence: Khek Yu Ho

Department of Medicine, Yong Loo Lin School of Medicine, National University of Singapore, NUHS Tower Block, 1E Kent Ridge Road, Level 11, Singapore 119228, Singapore

Tel: +65-6772-4362, Fax: +65-6779-4112, E-mail: mdchoky@nus.edu.sg ORCID: https://orcid.org/0000-0002-2932-1962

(c) This is an Open Access article distributed under the terms of the Creative Commons Attribution Non-Commercial License (http://creativecommons.org/ licenses/by-nc/3.0) which permits unrestricted non-commercial use, distribution, and reproduction in any medium, provided the original work is properly cited. lesions are situated at difficult anatomical locations to access, ESD can result in high rates of adverse events. In view of these challenges, endoscopic full thickness resection (EFTR) is the preferred resection technique for this subgroup of tumors.

In this review, we discuss the indications for EFTR. We also describe the technical details of various EFTR techniques, including their advantages and disadvantages. Finally, we discuss the current challenges among endoscopists who are keen to adopt EFTR in their clinical practice, and how our novel robotic endoscopic platform with suturing capabilities can overcome these technical challenges.

\section{INDICATIONS FOR ENDOSCOPIC FULL THICKNESS RESECTION}

EFTR is especially useful in the management of lesions where ESD produces suboptimal results. 


\section{Lesions arising from or infiltrating the deeper layers of submucosa or muscularis propria}

EFTR is especially beneficial in the treatment of submucosal tumors. These include gastrointestinal subepithelial tumors and T1 carcinoma with no lymphatic and/or vascular invasion. Tumors that infiltrate into the muscularis propria, such as gastrointestinal stromal tumors (GISTs), leiomyoma and schwannoma, can also benefit from EFTR.

A retrospective study conducted by Kuellmer et al. in 156 patients, showed that EFTR is technically feasible and safe in cases of early colorectal cancer identified via histology. ${ }^{5}$ Technical success and R0 resection were achieved in 92.3\% and $71.8 \%$ of the cases respectively. Severe procedure-related adverse events occurred in only $3.9 \%$ of patients. ${ }^{5}$

\section{Non-lifting lesions}

Non-lifting lesions can occur due to fibrosis or scarring. They can also develop due to recurrence of epithelial neoplasms following endoscopic mucosal resection or ESD procedure. ${ }^{6}$ In earlier times, non-lifting lesions were a contraindication for standard polypectomy. However, with the introduction of EFTR, non-lifting lesions can now be resected with high rates of R0 resection and low rates of perforation.

A retrospective study conducted by Kuellmer et al. showed that the rate of $\mathrm{R} 0$ resection was $60.9 \%$ in the group with non-lifting lesions. ${ }^{5}$ The final histology revealed adenocarcinoma in $100 \%$ of the specimens.

\section{Lesions at difficult anatomical locations to access}

Resection of the lesions situated at the appendiceal orifice or within the diverticulum can be extremely challenging using conventional techniques. Using EFTR to treat these lesions can lower the rates of adverse events, particularly iatrogenic perforations.

In the upper gastrointestinal tract, ESD is more challenging for lesions located in the cardia or along the lesser curvature, due to the need for retroflexion. Lesions in the gastroduodenal region also pose significant challenges to the endoscopist. For these lesions, the rate of adverse events can be lowered by using EFTR.

\section{TECHNIQUES FOR ENDOSCOPIC FULL THICKNESS RESECTION}

Since the introduction of EFTR, numerous techniques have been developed. We describe here, the brief technical details of each technique, and provide evidences of the advantages

Table 1. Comparison of Endoscopic Full Thickness Resection Techniques

\begin{tabular}{|c|c|c|}
\hline $\begin{array}{l}\text { Endoscopic full thickness } \\
\text { resection techniques }\end{array}$ & Advantages & Disadvantages \\
\hline \multicolumn{3}{|l|}{ A. Non-tunneling techniques } \\
\hline $\begin{array}{l}\text { Endoscopic submucosal } \\
\text { excavation }\end{array}$ & $\begin{array}{l}\text { - Superior R0 resection rates as compared } \\
\text { to endoscopic submucosal dissection }\end{array}$ & - High perforation rates \\
\hline $\begin{array}{l}\text { Endoscopic full thickness } \\
\text { resection with secondary } \\
\text { closure (exposed endoscopic } \\
\text { full thickness resection) }\end{array}$ & - High technical success rates & $\begin{array}{l}\text { - Risk of intraperitoneal contamination with gastric con- } \\
\text { tents } \\
\text { - Risk of intraperitoneal dissemination of tumor cells } \\
\text { - Lack of endoscopic instruments to close large defects }\end{array}$ \\
\hline \multicolumn{3}{|l|}{ B. Tunneling techniques } \\
\hline $\begin{array}{l}\text { Submucosal tunneling with } \\
\text { endoscopic resection }\end{array}$ & $\begin{array}{l}\text { - Minimal risk of intraperitoneal contami- } \\
\text { nation with gastric contents } \\
\text { - Minimal risk of intraperitoneal dissemi- } \\
\text { nation of tumor cells }\end{array}$ & $\begin{array}{l}\text { - Not always anatomically feasible to create a submucosal } \\
\text { tunnel }\end{array}$ \\
\hline \multicolumn{3}{|l|}{ C. Collaborative techniques } \\
\hline $\begin{array}{l}\text { Laparoscopic and endoscopic } \\
\text { cooperative surgery }\end{array}$ & $\begin{array}{l}\text { - Functional and anatomical preservation } \\
\text { of gastrointestinal tract by precise deter- } \\
\text { mination of tumor boundary }\end{array}$ & $\begin{array}{l}\text { - Risk of intraperitoneal contamination with gastric con- } \\
\text { tents } \\
\text { - Risk of intraperitoneal dissemination of tumor cells }\end{array}$ \\
\hline \multicolumn{3}{|l|}{ D. Non-exposed techniques } \\
\hline $\begin{array}{l}\text { Non-exposed endoscopic } \\
\text { wall-inversion surgery }\end{array}$ & $\begin{array}{l}\text { - Minimal risk of intraperitoneal contami- } \\
\text { nation with gastric contents } \\
\text { - Minimal risk of intraperitoneal dissemi- } \\
\text { nation of tumor cells }\end{array}$ & $\begin{array}{l}\text { - Tumor retrieval route limits applicability to small tu- } \\
\text { mors }\end{array}$ \\
\hline
\end{tabular}


and disadvantages of each method. Table 1 can be used as a roadmap for endoscopists to decide which technique is best suited for their patient, depending on the tumor size and the availability of equipment and expertise.

\section{A. Non-tunneling techniques}

\section{Endoscopic submucosal excavation}

\section{Technical details}

In endoscopic submucosal excavation (ESE), no circumferential incision is performed. Instead, the mucosa overlying the lesion is incised to allow the subepithelial tumor to be dissected from the submucosal or muscularis propria layer. Subsequently, endoscopic clips are used to close the site of incision (Fig. 1) ${ }^{7}$

\section{Advantages}

ESE has been used effectively in the treatment of esophageal and gastric subepithelial tumors. R0 resection rates with ESE are higher compared to the traditional ESD techniques. Ye et al. showed that $95.6 \%$ of small esophageal subepithelial tumors originating from the muscularis propria could be successfully resected with negative margins using ESE. ${ }^{8}$ The high rate of success of ESE for resections of gastric subepithelial tumors was also demonstrated by Jeong et al. ${ }^{9}$

\section{Disadvantages}

Despite the high R0 resection rates, perforation rates remain as high as $13 \% .{ }^{10}$ During resection, there is loss of air insufflation, resulting in collapse of the wall of the gastrointestinal tract, and a significantly restricted view of the operative field. The analysis by Jeong et al. showed that perforations were more commonly associated with GISTs and schwannomas, as these tumors had incomplete tumor capsules and were tightly adherent to the surrounding tissue. ${ }^{9}$ In addition, the relatively thin wall of the gastric fundus and its location are a challenge for endoscopic access. This predisposes fundal tumors to higher rates of perforation, compared to other sites in the stomach $(p<0.001){ }^{9}$

\section{Endoscopic full-thickness resection with secondary closure (exposed EFTR)}

\section{Technical details}

To reduce the rates of perforation, Kuellmer et al. developed a technique for performing exposed EFTR with secondary closure. ${ }^{5}$ When performing exposed EFTR, a full thickness resection device such as the Oversco Endoscopy is required. The lesion is first marked, and is then grasped and pulled into the cap, attached above the scope. The lesion is resected after applying the clip (Fig. 2).

\section{Advantages}

Kuellmer et al. demonstrated technical success in $92.3 \%$ of the resections using this technique. ${ }^{5}$ Procedure-related adverse events were documented in $14 \%$ of the patients, and $3 \%$ of the patients required surgical intervention for the management of iatrogenic perforation. ${ }^{5}$

\section{Disadvantages}

As seen in all exposed EFTR techniques, there is a risk of

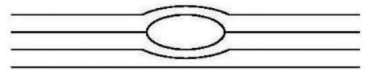

This figure represe the four layers of the gastric wall (mucosa, submucosa, muscularis propria and serosa), with a tumor arising from the submucosa layer.

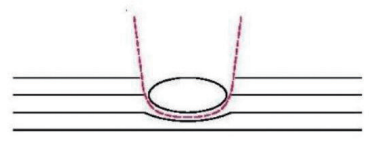

The subepithelial tumor is then incised.

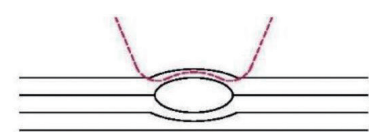

An incision is made in the mucosa layer.

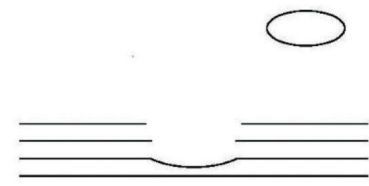

The subepithelial tumor is then removed, leaving a defect in the mucosal and submucosal layer.

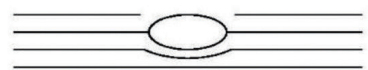

After an incision is made in the mucosal layer, the subepithelial tumor becomes visible.

Fig. 1. Technique of endoscopic submucosal excavation. 
intraperitoneal contamination by the gastric contents, and dissemination of tumor cells within the peritoneal cavity. ${ }^{11}$ Moreover, if the size of the tumor is large, closure of the defect is technically challenging. Current endoscopic instruments are not ideally suitable for performing full-thickness suturing while maintaining insufflation of the gastrointestinal tract.

\section{B. Tunneling techniques}

\section{Submucosal tunneling with endoscopic resection}

\section{Technical details}

In submucosal tunneling with endoscopic resection (STER), a submucosal fluid cushion is created by injecting a mixed solution of normal saline, indigo carmine, and epinephrine, along the proximal margin of the tumor. This creates a submucosal tunnel between the mucosal and muscular layer. This submucosal tunnel should ideally end $1 \mathrm{~cm}$ distal to the tumor, to ensure adequate working space and satisfactory endo- scopic view of the tumor. The crux of the STER procedure is the creation of a mucosal incision with submucosal tunneling of the endoscope along the fluid cushion. This ensures that there remains an intact cover of mucosa during the resection. The tumor is then enucleated and extracted. After hemostasis is performed, the entrance to the submucosal tunnel is closed with endoscopic clips (Fig. 3). ${ }^{12}$

\section{Advantages}

A retrospective study of 180 patients was performed by Chen et al. ${ }^{12}$ All patients had upper gastrointestinal subepithelial tumors that were resected using the STER technique. Only 1 patient required additional surgery. Adverse events were encountered in $8.3 \%$ of the patients, with no severe mediastinal or intra-abdominal infections. Of these, 177 patients were followed up for a median duration of 36 months, and all of them were free from local recurrences or distant metastasis. Thus, their study showed that STER is an effective and safe resection technique for upper gastrointestinal subepithelial tumors.

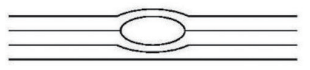

This figure represents the four layers of the gastric wall (mucosa, submucosa, muscularis propria and serosa), with a tumor arising from the submucosa layer.
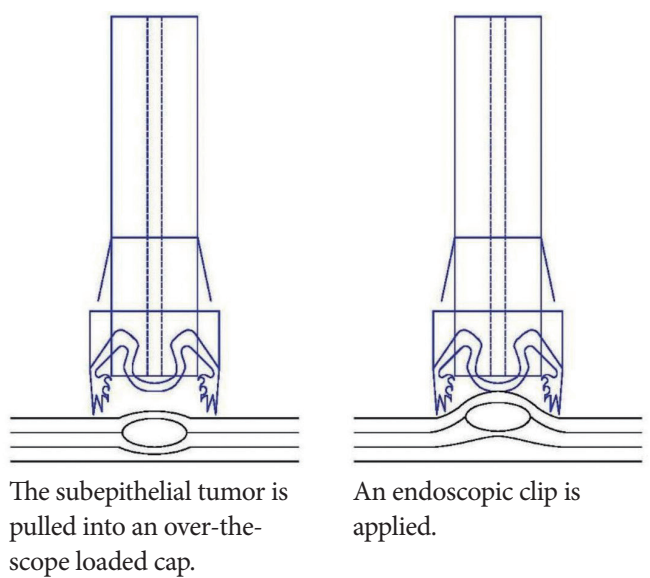

An endoscopic clip is applied.

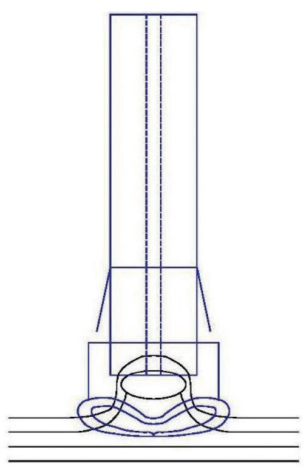

The subepithelial tumor is resected above the endoscopic clip.

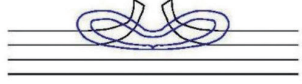

The mucosa and submucosal defects are closed by the previously applied endoscopic clip.

Fig. 2. Technique of exposed endoscopic full thickness resection

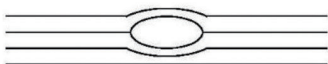

This figure represents the four layers of the gastric wall (mucosa, submucosa, muscularis propria and serosa), with a tumor arising from the submucosa layer.

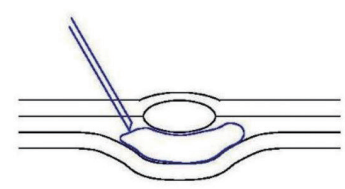

Injection is performed along the proximal margin of the tumor, ending at least $1 \mathrm{~cm}$ distal to the tumor. The injection creates a submucosal fluid cushing.

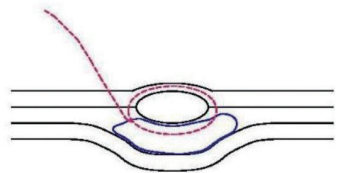

The subepithelial tumor is excised. Mucosal layer remains intact.

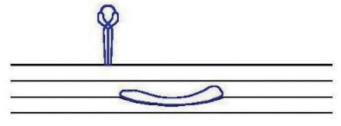

Entrance to submucosal fluid tunnel is closed using an endoscopic clip.

Fig. 3. Technique of submucosal tunneling with endoscopic resection 
The use of a submucosal tunnel in STER also reduces the likelihood of intraperitoneal contamination by gastric contents, and minimizes the likelihood of intraperitoneal tumor cell dissemination. ${ }^{6}$ This promotes faster wound healing and patient recovery.

\section{Disadvantages}

In certain parts of the gastrointestinal tract, creation of a submucosal tunnel might be anatomically challenging. ${ }^{6}$ In such cases, it would be more appropriate to perform non-tunneling EFTR methods.

\section{Collaborative techniques}

One of the most common collaborative techniques between surgeons and endoscopists is laparoscopic and endoscopic cooperative surgery (LECS). LECS is an accepted technique of minimally invasive laparoscopic wedge resection, and is commonly used during surgery for GISTs.

\section{Technical details}

In this technique performed under direct endoscopic visualization, the tumor is resected en bloc in a full-thickness fashion using endoscopic and/or laparoscopic techniques. Laparoscopic staplers or laparoscopic suturing is then used to close the defect in the gastric wall (Fig. 4). ${ }^{13}$

\section{Advantages}

The main advantage of LECS is its precise determination of the tumor boundary on endoscopy. This allows for R0 resection while minimizing the amount of gastric tissue resected. This leads to functional and anatomical preservation of the gastrointestinal tract. $^{12}$

\section{Disadvantages}

However, an innate flaw of LECS is the deliberate gastric perforation that can be associated with peritoneal contamination by tumor cells dispersed from the primary tumor and bacterial infection from intragastric luminal contents.

\section{Non-exposed techniques}

\section{Technical details}

To prevent spillage of the gastric intraluminal contents into the peritoneal cavity, Mitsui et al. described a type of LECS called non-exposed endoscopic wall-inversion surgery (NEWS). ${ }^{14}$ In NEWS, markings are made on the mucosa around the lesion, as well as on the serosal surface. The submucosal layer is then injected with a solution and circumferential seromuscular layer incision is performed. Suturing is then performed in the seromuscular space with inversion of the lesion using a gauze spacer, causing protrusion of the gastric mucosa due to the inverted tissue. The muco-submucosal layer is then incised and endoscopic clips are placed to close
Intraluminal

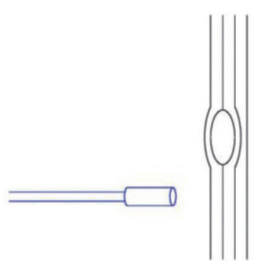

Extraluminal

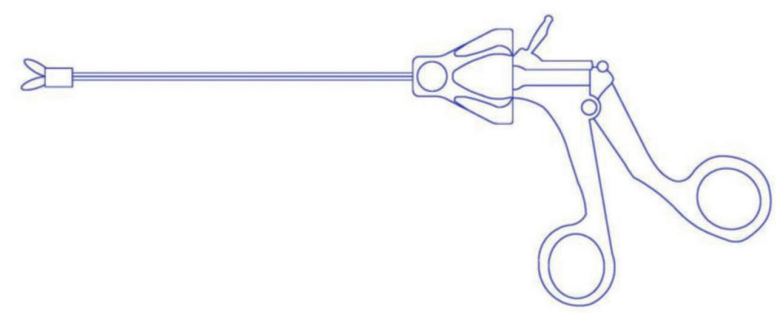

The endoscope is positioned intraluminally. The laparoscopic instrument in placed extraluminally within the peritoneal cavity.

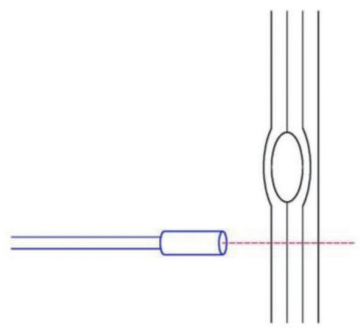

Endoscopic incision is performed.

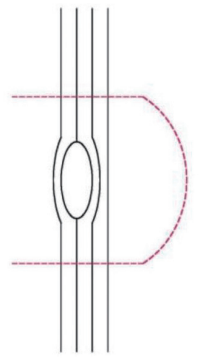

Full thickness dissection continued with endoscopic and laparoscopic techniques.

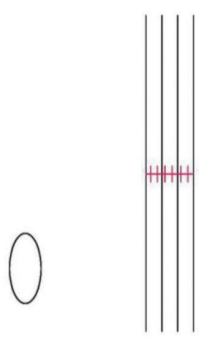

Subepithelial tumor completely excised. Incision closed using laparoscopic stapling device.
Fig. 4. Technique of laparoscopic and endoscopic cooperative surgery. 
the artificial linear ulcer. The specimen is then extracted orally using an endoscopic retrieval device. The crux of NEWS is to first place the sutures to secure the resection site, and then complete the resection (Fig. 5).

\section{Advantages}

With suturing performed prior to resection, it reduces the likelihood of peritoneal contamination by intragastric contents, and minimizes the dissemination of tumor cells. This overcomes the innate flaw of LECS with its deliberate gastric perforation.

Mitsui et al. described the use of NEWS in 28 patients with gastric GISTs. ${ }^{14}$ NEWS was found to be feasible for the treatment of small GISTs. ${ }^{14}$ NEWS is especially suitable for small GISTs with mucosal ulceration, where opening of the gastric wall by full-thickness enucleation would not be optimal.

\section{Disadvantages}

However, the major drawback of NEWS is its limited use in small tumors, because the esophageal orifice and gastroesophageal junction limits the tumor retrieval route. Therefore, careful and precise evaluation of the tumor size pre-operatively is paramount to the success of NEWS.

\section{CHALLENGES IN ENDOSCOPIC FULL THICKNESS RESECTION}

Despite the advancement in EFTR techniques, EFTR has not been adopted in routine endoscopic practice. An international survey conducted by Goto et al. in 2016 (personal communication) attempted to elucidate the reasons for the lack of wide adoption of this technique. Sixty percent of the respondents indicated that they had direct experience in performing endoscopic resection under laparoscopic assistance. However, $32 \%$ of the respondents indicated by way of personal communication that laparoscopic closure by hand-suturing was technically difficult and/or very difficult.

\section{SOLUTIONS TO OVERCOME THE TECHNICAL CHALLENGES IN ENDOSCOPIC FULL THICKNESS RESECTION}

Due to the technical difficulties in performing laparoscopic and endoscopic suturing using the currently available instruments, it is paramount to identify what an ideal EFTR system
Intraluminal

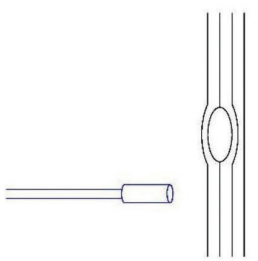

Extraluminal

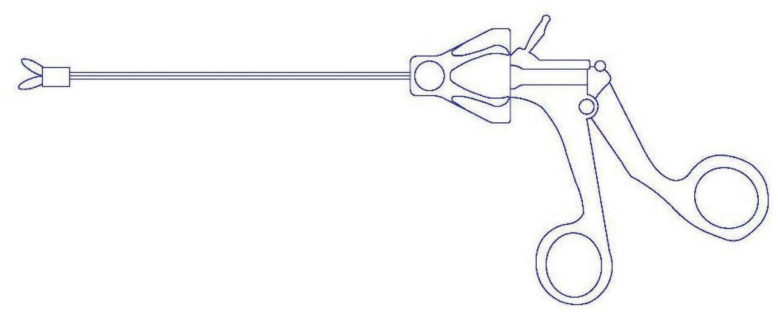

The endoscope is positioned intraluminally. The laparoscopic instrument in placed extraluminally within the peritoneal cavity.

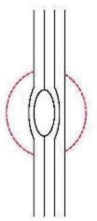

Markings are made in the mucosal and serosal layer around the lesion.

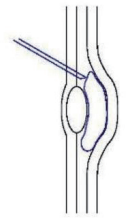

Injection into
submucosal
layer using
endoscopic
needle.
needle.

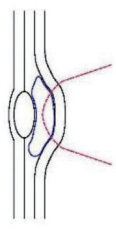

$$
\begin{aligned}
& \text { Incision made } \\
& \text { into } \\
& \text { muscularis } \\
& \text { propria and } \\
& \text { serosal layer } \\
& \text { using } \\
& \text { laparoscopic } \\
& \text { instrument. }
\end{aligned}
$$

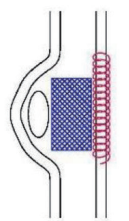

Insertion of a gauze to invert the lesion intraluminally. Muscularis propria and serosal layer defects are closed by laparoscopic suturing.
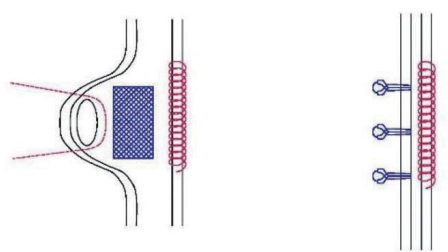

Subepithelial tumor excised with incision into mucosal and submucosal layers.
Defect in mucosal and submucosal layer closed with endoscopic clips.

Fig. 5. Technique of non-exposed endoscopic wall-inversion surgery 
should encompass. The ideal EFTR system should have two components-first, the system should allow for good maneuvering and triangulation; second, the system should allow for safe and reliable closure of any gastrointestinal tract defects.

Currently, there are four FDA approved endoscopic suturing devices-InScope Tissue Apposition System (Ethicon Endo-Surgery, Cincinnati, OH, USA), g-Prox Tissue Approximation Device (USGI; USGI Medical, San Clemente, CA, USA), OverStitch (Apollo Endosurgery, Austin, TX, USA), and OTSC (Ovesco Endoscopy, Tuebingen, Germany). However, the major challenge of these mechanically driven platforms is that they do not allow for hand suturing with serosa-to-serosa apposition.

Recently, Endomina (Endotools SA, Gosselies, Belgium), a single-use triangulation robotic platform was introduced for endoluminal suturing. However, the two operating arms are inserted over-the-scope using guidewires, instead of through the existing endoscopic channels. This results in a large and bulky instrument with potential risk of trauma to the upper gastrointestinal tract during insertion.

We have developed a Master and Slave TransEndoluminal Robot (MASTER) (EndoMaster Pte. Ltd., Singapore), which is equipped with a multitasking robotic endoscopic platform and interchangeable robotic arms (Fig. 6). The major benefit of this system is the usability of the endoscopic instruments in triangulation, and the ability to be rotated like human wrists. This is possible because of the seven degrees of freedom provided by the robotic wrists in the endoscopic end effectors. ${ }^{15}$

We first performed an animal study in 2014 using two live porcine models to determine the feasibility of EFTR using the MASTER system. ${ }^{16}$ In this study, we successfully performed two cases of EFTR with no injury to the surrounding structures throughout the procedure. We closed the gastric defect using Overstitch, with satisfactory gastric distention and no

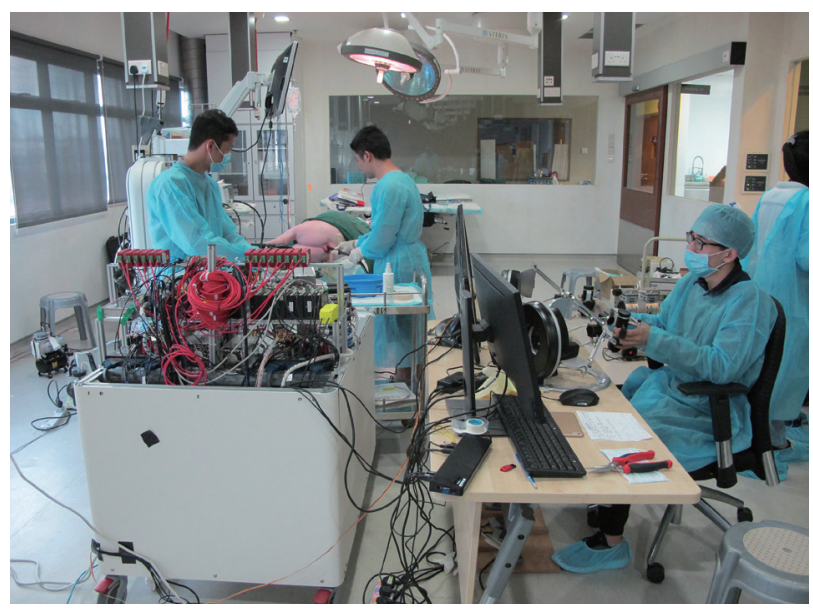

Fig. 6. Multitasking robotic endoscopic platform. subsequent air leak. We demonstrated that the MASTER system affords superior maneuverability and triangulation compared to the currently available endoscopic instruments.

To ensure safe and reliable closure of the gastrointestinal tract defects, we developed a novel suturing device that can be used with the MASTER system in 2018. This novel suturing device consists of a needle driver and a grasper that can be inserted through-the-scope via the existing endoscopic channels (Fig. 7). Both robotic arms can be rotated up to 360 degrees. The needle driver has a locking mechanism, which allows the needles to be switched between its two jaws. An animal study performed using the MASTER system equipped with the suturing device showed that the use of a robot for endoscopic suturing is superior and effective for surgical suturing and creating the knot (Fig. 8). ${ }^{17}$

\section{CONCLUSIONS}

Given the limitations of ESD in the management of complex lesions, EFTR is especially useful for gastrointestinal tumors arising from deeper layers such as the submucosa or muscularis propria. EFTR is also beneficial for non-lifting lesions, and lesions located at difficult to access anatomical locations.

Many techniques have been developed to allow endoscopists to perform EFTR. However, despite multiple techniques, EFTR has not been widely adopted in routine clinical practice. This is due to the technical challenges faced by endoscopists using the currently available endoscopic devices. The lack of maneuverability and triangulation makes it technically demanding for tumor resection to be performed endoscopically. Moreover, the inability to secure reliable wound closure with the current available systems continues to be a challenge for

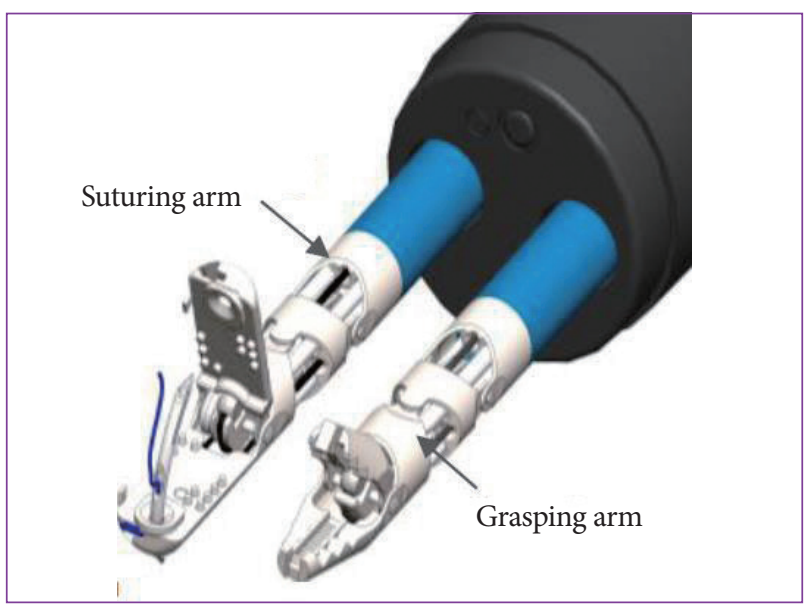

Fig. 7. Robotic arms inserted through working channels of the endoscope. 


\section{$C_{\text {clinical endoscopy }}$}

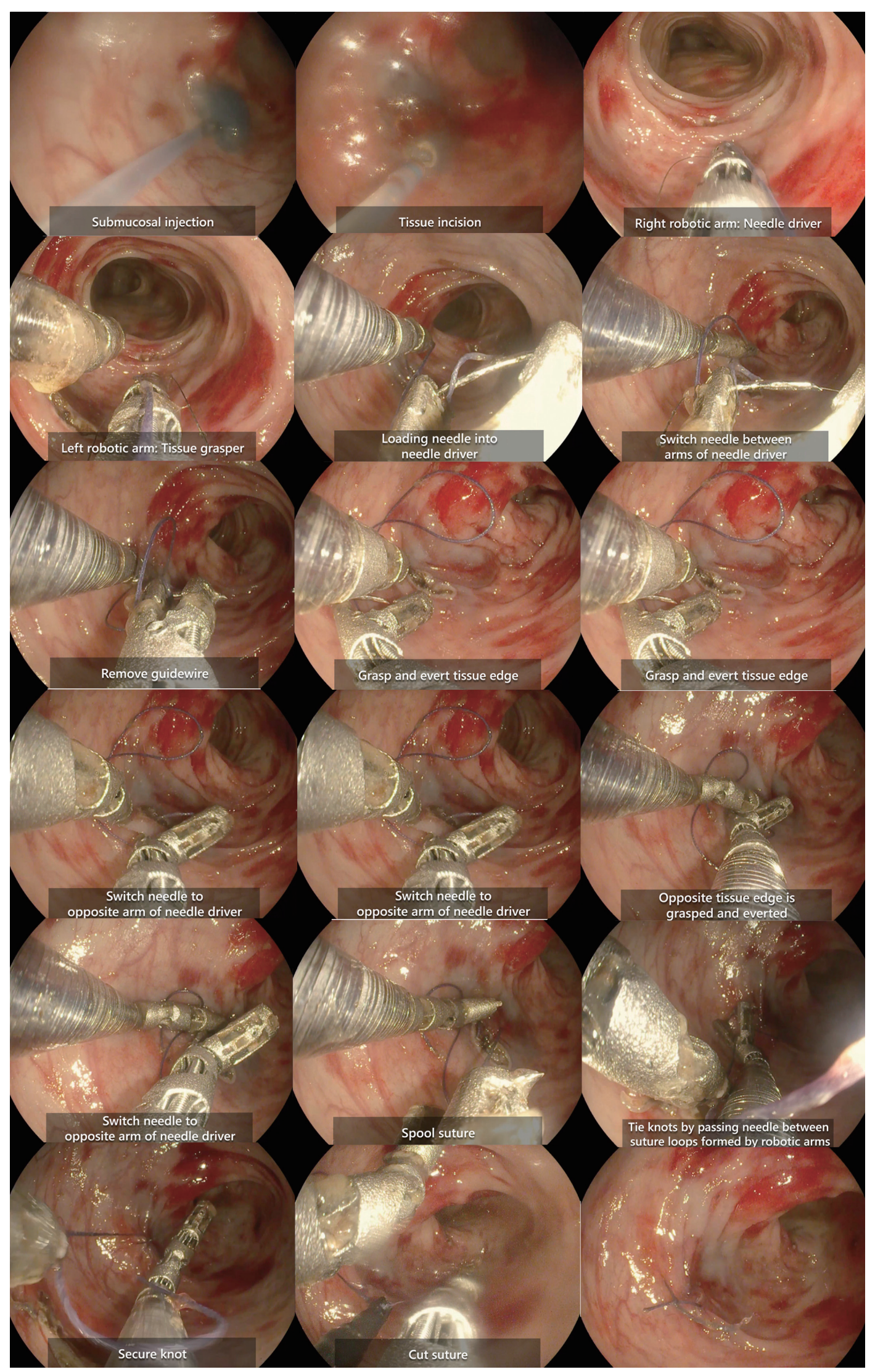

Fig. 8. Suturing using the Master and Slave TransEndoluminal Robot system. 
endoscopists.

We have since developed a robotic endoscopic platform with suturing capabilities. Through our studies, we have demonstrated that the robotic endoscopic platform with suturing capabilities offers a promising way to overcome many limitations of the current endoscopic techniques used in EFTR. With the benefits offered by this system and its ease of use in the clinical setting, we believe that more endoscopists would adopt EFTR in clinical practice in the future.

\section{Conflicts of Interest}

Khek Yu Ho is the co-founder of EndoMaster Pte Ltd., Singapore. The other author has no financial conflicts of interest.

\section{ORCID}

Hung Leng Kaan: https://orcid.org/0000-0002-0526-9100

\section{REFERENCES}

1. Chung IK, Lee JH, Lee SH, et al. Therapeutic outcomes in 1000 cases of endoscopic submucosal dissection for early gastric neoplasms: Korean ESD Study Group multicenter study. Gastrointest Endosc 2009;69:12281235.

2. Chun SY, Kim KO, Park DS, et al. Endoscopic submucosal dissection as a treatment for gastric subepithelial tumors that originate from the muscularis propria layer: a preliminary analysis of appropriate indications. Surg Endosc 2013;27:3271-3279.

3. He Z, Sun C, Wang J, et al. Efficacy and safety of endoscopic submucosal dissection in treating gastric subepithelial tumors originating in the muscularis propria layer: a single-center study of 144 cases. Scand J Gastroenterol 2013;48:1466-1473.

4. Białek A, Wiechowska-Kozłowska A, Pertkiewicz J, et al. Endoscopic submucosal dissection for treatment of gastric subepithelial tumors (with video). Gastrointest Endosc 2012;75:276-286.

5. Kuellmer A, Mueller J, Caca K, et al. Endoscopic full-thickness resection for early colorectal cancer. Gastrointest Endosc 2019;89:1180-1189.el.

6. Dellatore P, Bhagat V, Kahaleh M. Endoscopic full thickness resection versus submucosal tunneling endoscopic resection for removal of submucosal tumors: a review article. Transl Gastroenterol Hepatol 2019;4:45.

7. Kim SY, Kim KO. Endoscopic treatment of subepithelial tumors. Clin Endosc 2018;51:19-27.

8. Ye LP, Zhu LH, Zhou XB, Mao XL, Zhang Y. Endoscopic excavation for the treatment of small esophageal subepithelial tumors originating from the muscularis propria. Hepatogastroenterology 2015;62:65-68.

9. Jeong ID, Jung SW, Bang SJ, Shin JW, Park NH, Kim DH. Endoscopic enucleation for gastric subepithelial tumors originating in the muscularis propria layer. Surg Endosc 2011;25:468-474.

10. Liu BR, Song JT, Qu B, Wen JF, Yin JB, Liu W. Endoscopic muscularis dissection for upper gastrointestinal subepithelial tumors originating from the muscularis propria. Surg Endosc 2012;26:3141-3148.

11. Mori H, Rahman A, Kobara H, et al. Current status of exposed endoscopic full-thickness resection and further development of non-exposed endoscopic full-thickness resection. Digestion 2017;95:6-15.

12. Chen T, Zhou PH, Chu Y, et al. Long-term outcomes of submucosal tunneling endoscopic resection for upper gastrointestinal submucosal tumors. Ann Surg 2017;265:363-369.

13. Niimi K, Ishibashi R, Mitsui T, et al. Laparoscopic and endoscopic cooperative surgery for gastrointestinal tumor. Ann Transl Med 2017;5:187.

14. Mitsui T, Yamashita H, Aikou S, Niimi K, Fujishiro M, Seto Y. Non-exposed endoscopic wall-inversion surgery for gastrointestinal stromal tumor. Transl Gastroenterol Hepatol 2018;3:17.

15. Kaan HL, Ho KY. Robot-assisted endoscopic resection: current status and future directions. Gut Liver 2020;14:150-152.

16. Chiu PW, Phee SJ, Wang Z, et al. Feasibility of full-thickness gastric resection using master and slave transluminal endoscopic robot and closure by Overstitch: a preclinical study. Surg Endosc 2014;28:319-324.

17. Kaan HL, Ho KY. Endoscopic robotic suturing: the way forward. Saudi J Gastroenterol 2019;25:272-276. 